\title{
THE LIFE CYCLE OF \\ HETEROPODA VENATORIA (LINNAEUS) \\ (ARANEAE: HETEROPODIDAE) ${ }^{1,2}$
}

BY

John Ross 3 , David B. Richman 3 , Fadel Mansour 4 , Anne Trambarulo ${ }^{3}$, and W. H. Whitcomb ${ }^{3}$

The giant crab spider, Heteropoda venatoria (L.), is known to occur throughout much of the tropics and subtropics of the world where it is valued as a predator of cockroaches (Guthrie and Tindall 1968, Hughes 1977, Edwards 1979). Its feeding habits, like those of most spiders, vary somewhat and it has also been known to eat scorpions and bats (Bhattacharya 1941), although it is questionable as to whether it normally attacks such prey. This spider is often found associated with human habitation, possibly due to the abundance of prey (Subrahamanyam 1944, Edwards 1979). Although biological notes on $H$. venatoria have been published by several workers (Lucas 1871, Minchin 1904, Bristowe 1924, Bonnet 1930, Ori 1974, 1977), the only life history work to date was published by Bonnet (1932) and Sekiguchi (1943, 1944a,b, 1945). Bonnet (1932) based his study on only 12 spiders (of which seven matured) and lacked data on the postembryonic stages. Sekiguchi $(1943,1944 a, b$, 1945) presented a more nearly complete study, but the papers are difficult to translate and they still lack some data, especially in regard to variation in the number of instars and carapace width. We have raised $H$. venatoria in the laboratory and present here our data on life cycle of this important beneficial arthropod.

\section{Materials AND Methods}

Spiders were obtained from avocado groves in south Florida, near Homestead, Dade County. Egg sacs taken from our laboratory

\footnotetext{
'This study was partially supported by the United States-Israel BARD Fund as Research Project No. 1-2-79.

${ }^{2}$ Florida Agric. Exp. Sta. Journal Series No. 3798.

${ }^{3}$ Dept. of Entomology and Nematology, Univ. of Florida, Gainesville, FL 32611.

${ }^{4}$ Agricultural Research Organization, Newe Ya'ar, P.O. Haifa, Israel.
}

Manuscript received by the editor September 10, 1982 
population of $H$. venatoria were used to obtain data for eggs, first and second postembryos and spiderling instars. Immature spiders, through 4th-5th instars, were housed in Tygon ${ }^{\circledR}$ flexible plastic tubing, an adaptation of methods developed by Peck and Whitcomb (1967). Two tubing sizes were employed, $13 \mathrm{~mm}$ and $24 \mathrm{~mm}$ diameter. The smaller bore tubing was cut to $10 \mathrm{~cm}$ lengths while the 24 $\mathrm{mm}$ tubing was cut into lengths of $20 \mathrm{~cm}$ to house spiders from 5 th to 9th instars. Plastic foam culture-vial stoppers for 14-19 mm openings sealed the end of the tubing. Tube ends had only to be dipped into water weekly to maintain adequate moisture and humidity levels for the spiders. An open cell foam plug allowed for adequate ventilation while preventing the spider's escape from the tube. While these cages were not as large as would perhaps be ideal, they were easily maintained and stored in a relatively small area, and the spiders stayed healthy in them.

Moist cotton swabs were used to clean the tubes when clear vision into them was obscured by prey debris, spider wastes or mold. A rolled piece of $9 \mathrm{~cm}$ diameter filter paper was inserted into the $24 \mathrm{~mm}$ diameter tubes to further reduce cleaning frequency as the spiders tended to retreat onto the papers and defecate. Changing the filter paper at regular intervals maintained a high degree of sanitation.

Adult spiders were housed in 0.51 clear plastic cups. A heated cork boring tool was used to fashion holes in lids in which were inserted open cell, plastic culture tube stoppers which allowed for ventilation. Paper can lids were inverted as bottoms to the plastic cup spider cages and these were lined with $9 \mathrm{~cm}$ filter paper to facilitate cleaning.

First instar $\boldsymbol{H}$. venatoria were reared on adult vestigial-winged fruit flies, Drosophila melanogaster Meigen, for which the spiders showed a clear preference over an occasional cabbage looper larva, Trichoplusia ni (Hübner). Later instars were fed on adult native fruit flies (family Drosophilidae, genus unknown), which were larger than $D$. melanogaster, but the spiderlings showed greatest weight gain on mealworm larvae (Tenebrio molitor L.). Mealworms became the mainstay of the spiders' diet through the 10th and 11 th instars, when the spiders were fed adult crickets, Acheta domesticus (L.), to extend feeding intervals. Houseflies, Musca domestica L., were introduced in the pupal stage during the middle instars and were fed on as the adult flies emerged. 
Earlier instar spiders were maintained in a laboratory room and transferred during penultimate or adult stages to an environmental growth chamber. Temperatures in the room were stabilized at $27^{\circ} \mathrm{C}$ in the summer and $24^{\circ} \mathrm{C}$ in the winter, $\pm 2^{\circ} \mathrm{C}$. The spiders were kept under fluorescent lights. The eggs, postembryos, and first instars used for later observations were all maintained in the environmental chamber, which was kept at a constant $26.7^{\circ} \mathrm{C}$ on a $13: 11 \mathrm{~L}: \mathrm{D}$ light period. Humidity was controlled within the chamber by a supersaturated $\mathrm{NaCl}$ solution bath in a $20 \times 15 \times 8 \mathrm{~cm}$ tray. The tray was partially filled with small pebble-sized rocks to increase the surface area available for moisture exchange. The humidity control method was adapted from a technique described by Winston and Bates (1960) and it stabilized humidity levels within the $60-70 \%$ range as monitored by a hygrothermograph.

Mating was observed in plastic gerbil cages, which were modified to prohibit escapes by gluing taffeta-like cloth between the upper and lower portions of the cage.

Carapace widths were measured at the widest points with an ocular micrometer and a binocular microscope.

\section{RESULTS AND Discussion}

The courtship and mating of $H$. venatoria was described by Bonnet (1932) and Sekiguchi (1944b). Our observations generally agree with these published accounts except where noted in the following discussion. In the current study, males introduced to a cage with a female were observed to construct a sperm web approximately 2 hours prior to mating. After sperm induction male spiders groomed their pedipalps for 5-25 seconds. The males vibrated their bodies prior to mounting, as described in detail by Rovner (1980). After mounting, the male rubbed his first pair of legs on the female's abdomen before and sometimes during insertion of the pedipalps. Copulation occurred in bouts lasting from one to six hours over a period of 24 hours. The pedipalps were inserted alternately, for an average of 20.4 seconds for each insertion $(n=70, S D=6.8$ seconds). Bonnet (1932) reported that insertion lasted 6-7 seconds, not counting transfer time. Males were often cannibalized by the female after mating, which could account for the higher proportion of females to males found in the field. 
Approximately 12-14 days after mating, a circular, flattened, creamy white egg sac was produced by the female. The size of the sac ranged from 1.27 to $2.54 \mathrm{~cm}$ in diameter, and was from 3.18 to $6.35 \mathrm{~mm}$ thick. A network of silk was deposited on the underside of a flat surface, such as a leaf or plastic housing container lid. The eggs (each ca. $1.5 \mathrm{~mm}$ dia.) were deposited on this base, and covered with another layer of silk. After the egg sac was sealed around the edges and removed from the foundation, the female carried it with her pedipalps underneath her body during the incubation period. The female usually did not eat during this time. Infertile egg sacs were sometimes dropped or eaten by the female. A large number of infertile egg sacs (54\% of those produced in the laboratory) were constructed by the reared spiders. This might be expected due to the artificially imposed mating schedule. An average of 2.16 fertile egg sacs were produced per female, with five the highest number. An average of 163 eggs were laid in each fertile egg mass $(n=13 \mathrm{egg}$ masses, $\mathrm{SD}=28.97$ ) constructed by the experimental spiders. Bonnet (1932) reported 207 spiderlings emerging from the one egg mass from a female he had raised after obtaining it as an immature spider on bananas shipped from Africa. Sekiguchi (1944a) obtained 188-436 eggs/mass. In field observations we have found as many as 400 spiderlings in one egg sac. This may indicate that a high degree of variability in egg mass size is common. No data were taken on the numbers in consecutive egg sacs.

Peck and Whitcomb (1970) included a discussion of the postembryonic stages and reviewed the terminology used in the literature to describe them. The definitions used in the present study follow theirs and are given below to avoid confusion. The first postembryo is defined as being that stage after the chorion of the egg had been shed from most of the embryo, but remained as a crumpled mass at the posterior end. The second postembryo is defined as being that stage after the vitelline membrane had been shed and the embryo was completely free, with legs able to move. After the first molt the spiderling was considered to be a first instar. This molt occurred inside the egg sac. Bonnet (1932) and Sekiguchi (1944a) considered the emerged spiderlings to be second instars.

Several egg sacs were removed from $\mathrm{CO}_{2}$-anesthetized female spiders, opened, and placed in covered petri dishes for observation. The egg stage lasted from $8-14$ days $(n=6$ egg masses). Eclosion 
required approximately 4 hours and began with assistance from a pair of brownish "egg teeth" positioned on the patellar region of each pedipalp. The chorion was split anterioventral to the leg region with swelling pulses (30-60 seconds between pulses and 2-3 pulses per set) to about $2 / 3$ of the diameter of the embryo. The membranes were drawn towards the spinnerets by an alternating combination of abdominal contractions and withdrawal movements of the legs, similar to those observed in molting. The shed membrane remained attached to the spinnerets until it was discarded at the beginning of the second postembryonic stage along with the vitelline membrane surrounding the legs. The first postembryonic stage lasted from 1-2 days for four egg masses, but four other egg masses required 5-6 days to become second postembryos (total $n=8$ ).

During the second postembryonic stage the specimens were relatively quiescent. Eye pigment began to appear about the fifth or sixth day of the second postembryonic stage, with markings around the carapace margin and on the abdomen becoming visible soon afterwards. Dark setae appeared shortly before the first molt occurred. The duration of the second postembryonic stage was 9-10 days $(n=3)$. The first instar spiderlings remained in the egg sac approximately one week before emerging. One female which mated on the 28th of March, 1980, produced an egg sac 12 days later. From this egg sac 277 first instar spiderlings emerged after 32 days. All of the longevity data came from this group of spiderlings.

The duration of each instar is summarized in Table 1. Males were more likely (as noted by Bonnet 1932) to have one or two fewer molts than females, but this was not an absolute rule. Sekiguchi (1945) recorded complete data for only one female $H$. venatoria and found a total of 11 instars. He, however, apparently included the second postembryo as the first instar. Of the adults in our study for which complete data are available, the males $(n=3)$ had 8-10 instars $(\overline{\mathrm{X}}=8.7, \mathrm{SD}=1.2)$ which lasted 241.7 days $(\mathrm{SD}=56.2)$ and the females $(n=13)$ had $9-12$ instars $(\bar{X}=10.6, S D=1.0)$ which lasted 315.6 days $(\mathrm{SD}=21.0)$. The survival rate from first instar to adult in the laboratory was approximately $85 \%$. Total length of life from egg to death for our laboratory reared specimens was for males $(n=4) 355-586$ days $(\bar{X}=464.5$ days, $S D=112.0)$ and for females $(\mathrm{n}=16)$ 298-710 days $(\overline{\mathrm{X}}=580.3$ days, $\mathrm{SD}=128.6)$. Rovner (per. com.) found that some females of $H$. venatoria can survive for three years as adults in the laboratory. 
Table 1. Carapace width and duration of stadia in laboratory reared Heteropoda venatoria $(\mathrm{L}$.).

\begin{tabular}{|c|c|c|c|c|c|c|}
\hline Instar & $\begin{array}{c}\text { Carapace } \\
\text { width } \\
(\mathrm{mm})\end{array}$ & $\mathrm{n}$ & S.D. & $\begin{array}{l}\text { Duration } \\
\text { of stadium } \\
\text { (days) }\end{array}$ & $\mathrm{n}$ & S.D. \\
\hline 1st & 1.37 & 10 & 0.06 & 11.80 & 44 & 1.56 \\
\hline 2nd & 1.69 & 32 & 0.08 & 14.68 & 40 & 1.33 \\
\hline 3 rd & 2.20 & 27 & 0.13 & 26.32 & 37 & 5.28 \\
\hline 4th & 2.60 & 22 & 0.16 & 27.97 & 30 & 4.21 \\
\hline 5th & 3.10 & 41 & 0.26 & 28.52 & 31 & 5.67 \\
\hline 6th & 3.44 & 38 & 0.21 & 36.11 & 37 & 5.41 \\
\hline 7th & 3.79 & 39 & 0.16 & 36.42 & 33 & 6.60 \\
\hline 8th & 4.06 & 39 & 0.29 & 44.46 & 28 & 10.56 \\
\hline 9 th & 4.53 & 43 & 0.57 & 40.69 & 26 & 16.63 \\
\hline 10th & 5.36 & 43 & 0.55 & 35.48 & 23 & 12.57 \\
\hline 11 th & 6.67 & 33 & 0.71 & 28.11 & 9 & 6.57 \\
\hline $12 \mathrm{th}$ & - & - & - & 23.0 & 4 & 7.83 \\
\hline
\end{tabular}

The mean carapace width for each instar (not separated by sex) is shown in Figure 1 to have a nearly linear relationship with the stadia, as might be expected. This and the large number of stadia seem to agree with a suggestion made by Hagstrum (1971) that large spiders have added stadia, rather than accelerated growth between successive molts. Sekiguchi (1945) shows similar data for the female of $H$. venatoria in Japan. The carapace widths for our spiders are summarized in Table 1.

The ratio of females to males for reared spiders was 2.4/1 (22 females/9 males). The sex ratio for adult specimens collected in Homestead, Dade Co., FL, on August 14-19, 1981 was 3.4/1 (71 females/21 males). The sex ratio in Homestead might be due to cannibalism of the males by females, as mentioned previously. Of the females collected, $18.3 \%$ were carrying egg sacs, and all instars were observed to be present in the field. Summer seemed to be the major period of egg production both in the laboratory and in the field.

This spider probably offers one of the best possibilities for the use of spiders in biological control as it is well adapted for living in close association with humans and is readily reared. As these spiders habitually feed on cockroaches, $H$. venatoria behavior and ecology may be an important key in the biological control of one of mankind's oldest pests. 


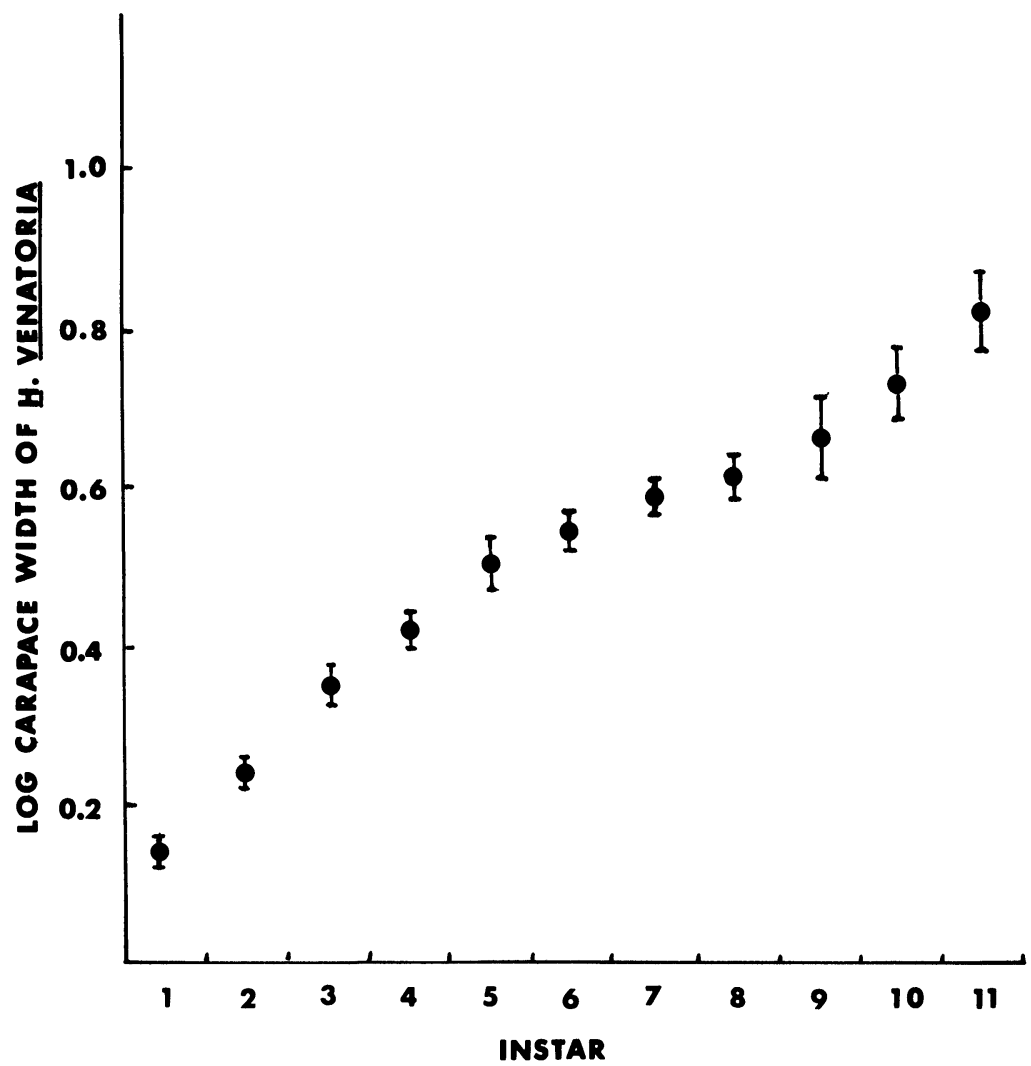

Figure 1. Relationship between logarithm of mean carapace with and stadia for laboratory-reared Heteropoda venatoria (L.). Standard deviations are shown for each point.

\section{ACKNOWLEDGEMENTS}

We would like to thank Dr. Stratton H. Kerr and Dr. Martin H. Muma for suggestions regarding the manuscript, and Takuji Hayakawa and John Watts for help with the collection and rearing of the spiders. Mr. Hayakawa also provided valuable help in translating the papers published by Dr. Sekiguchi.

\section{SUMMARY}

The giant crab spider, Heteropoda venatoria (L.) was reared in the laboratory. These spiders reached adulthood after 8-10 instars 
for the males and 9-12 instars for the females and took approximately one year to mature from the egg. The postembryonic stages were found to last approximately 2 weeks.

\section{Literature Cited}

Bhattacharya, G. C. 1941. Food and habits of the house-spider (Heteropoda venatoria Linn.). J. Bombay Nat. Hist. Soc. 42(4):821-5.

Bonnet, P. 1930. Observation sur deux Hetéropodes de la Guinée, etc. Ann. Soc. Entomol. France 99:49-64.

Bonnet, P. 1932. Cycle vital de Heteropoda regia Fabr. Livre du Centenaire Soc. Entomol. France: 497-503.

Bristowe, W. S. 1924. Notes on the habits of insects and spiders in Brazil. Trans. Entomol. Soc. London, 1924:475-504.

Edwards, G. B. 1979. The giant crab spider, Heteropoda venatoria (Linnaeus) (Araneae: Sparassidae). Florida Dept. Agric. Entomol. Circ. 205:1-2.

Guthrie, D. M. AND A. R. Tindall. 1968. The biology of the cockroach. Edward Arnald Publ. Ltd.

Hagstrum, D. W. 1971. Carapace width as a tool for evaluating the rate of development of spiders in the laboratory and the field. Ann. Entomol. Soc. Amer. 64:757-60.

Hughes, I. W. 1977. Cockroaches. Bermuda Dept. Agric. and Fish. Monthly Bull. 47(9):69-72.

LuCAS, H. 1871. Observations sur une ponte d'Olios venatorius. Ann. Soc. Entomol. France Bull. 5th Ser, 143:43, 58, 60 and 64.

Minchin, E. A. 1904. Exhibition of a specimen of the spider Heteropoda regia, captured at University College, London. Proc. Zool. Soc. London, 1:229.

OrI, M. 1974. Studies on spiders as natural enemies of insect pests. 1. Observations on the spiders in houses in Nagasaki prefecture [in Japanese, English summary]. Japan J. Sanit. Zool. 25(2):153-60.

ORI, M. 1977. Studies on spiders as natural enemies of insect pests. 5. Species of spiders as natural enemies of the house fly, and evaluation of their predacious capacities [in Japanese, English summary]. Japan J. Sanit. Zool. 28(2):175-8.

Peck, W. B., AND W. H. Whitcomb. 1967. An adaptable method for rearing spiders and cannibalistic insects. Turtox News 45(10): 242-4.

Peck, W. B., AND W. H. Whitcomb. 1970. Studies on the biology of a spider, Chiracanthium inclusum (Hentz). Arkansas Agric. Exp. Stn. Bull. 753:1-76.

RovNer, J. S. 1980. Vibration in Heteropoda venatoria (Sparassidae): A third method of sound production in spiders. J. Arachnol. 8:193-200.

SeKIGUCHI, K. 1943. Life history of Heteropoda venatoria Linnaeus [in Japanese]. Acta Arachnol. 8(3):66-77.

Sekiguchi, K. 1944a. Life history of Heteropoda venatoria Linnaeus 2 [in Japanese]. Acta Arachnol. 8(4):98-117.

Sekiguchi, K. 1944b. Life history of Heteropoda venatoria Linnaeus 3 [in Japanese]. Acta Arachnol. 9(1/2):1-21. 
SekiguChI, K. 1945. Life history of Heteropoda venatoria Linnaeus 4 [in Japanese]. Acta Arachnol. 9(3/4):107-111.

Subrahmanyam, T. V. 1944. Reoccurrence of the house spider (Heteropoda venatoria) in the field. J. Bombay Nat. Hist. Soc. 44(3):493.

Winston, P. W., AND D. H. Bates. 1960. Saturated solutions for the control of humidity in biological research. Ecology 41(1):232-7. 

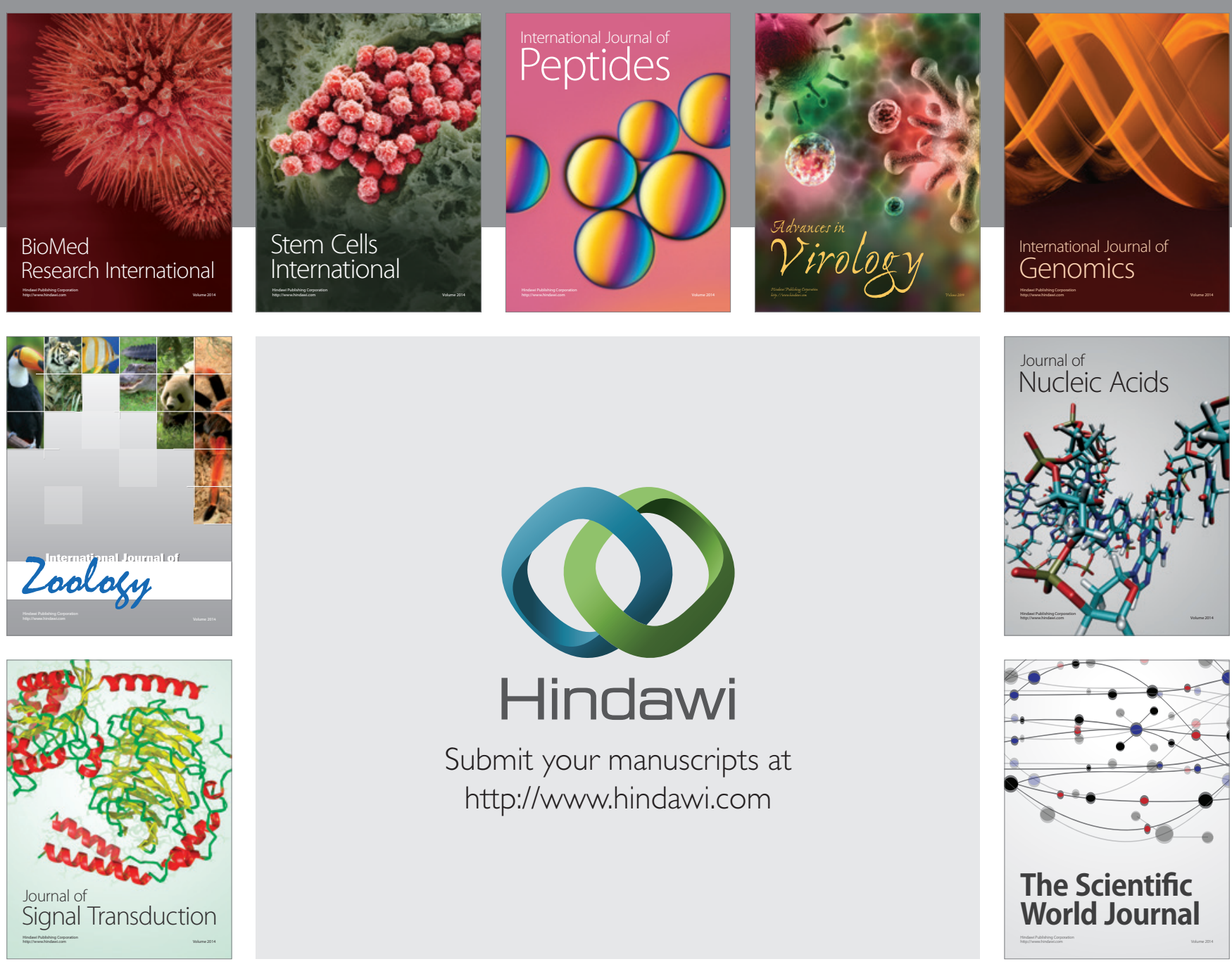

Submit your manuscripts at

http://www.hindawi.com
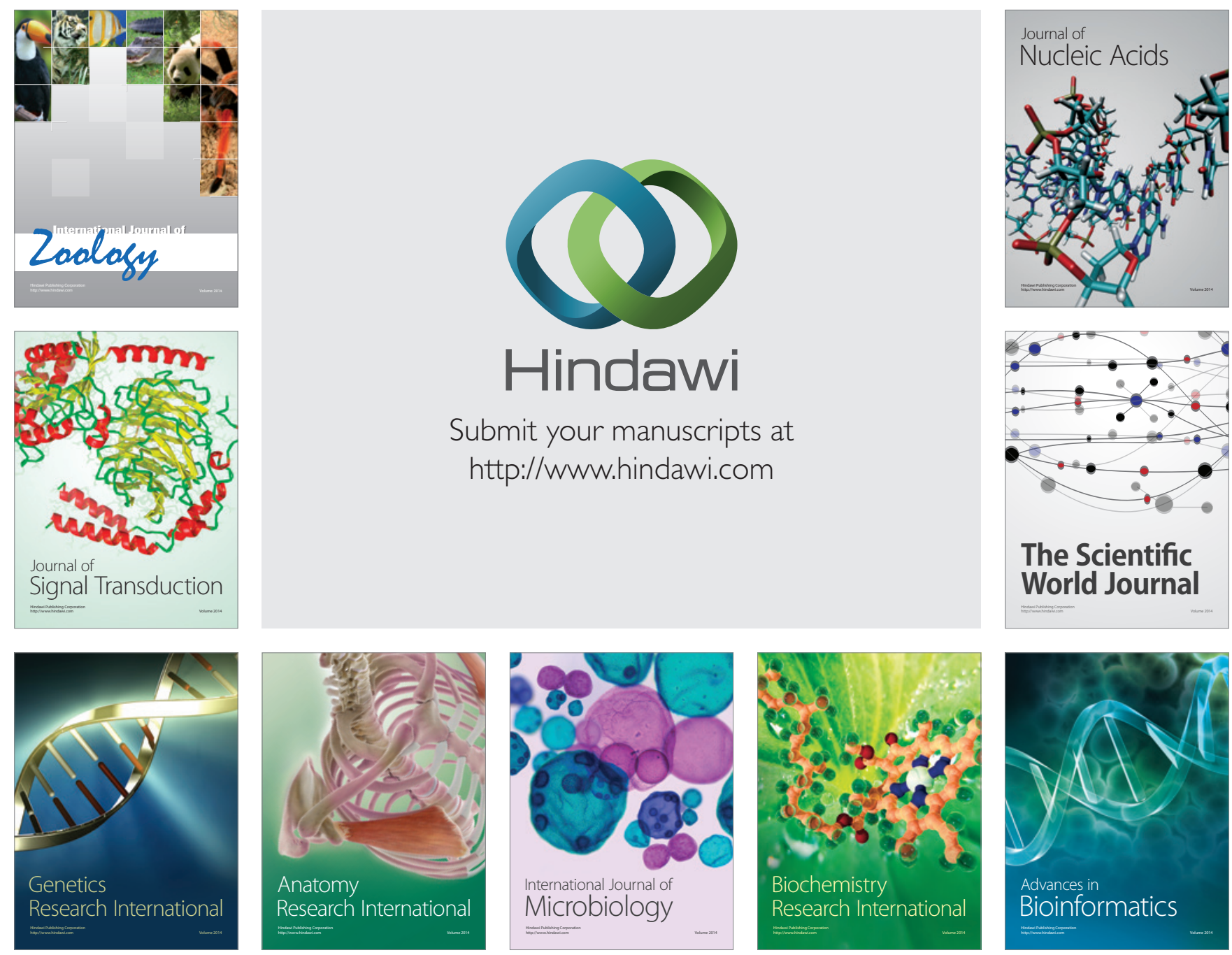

The Scientific World Journal
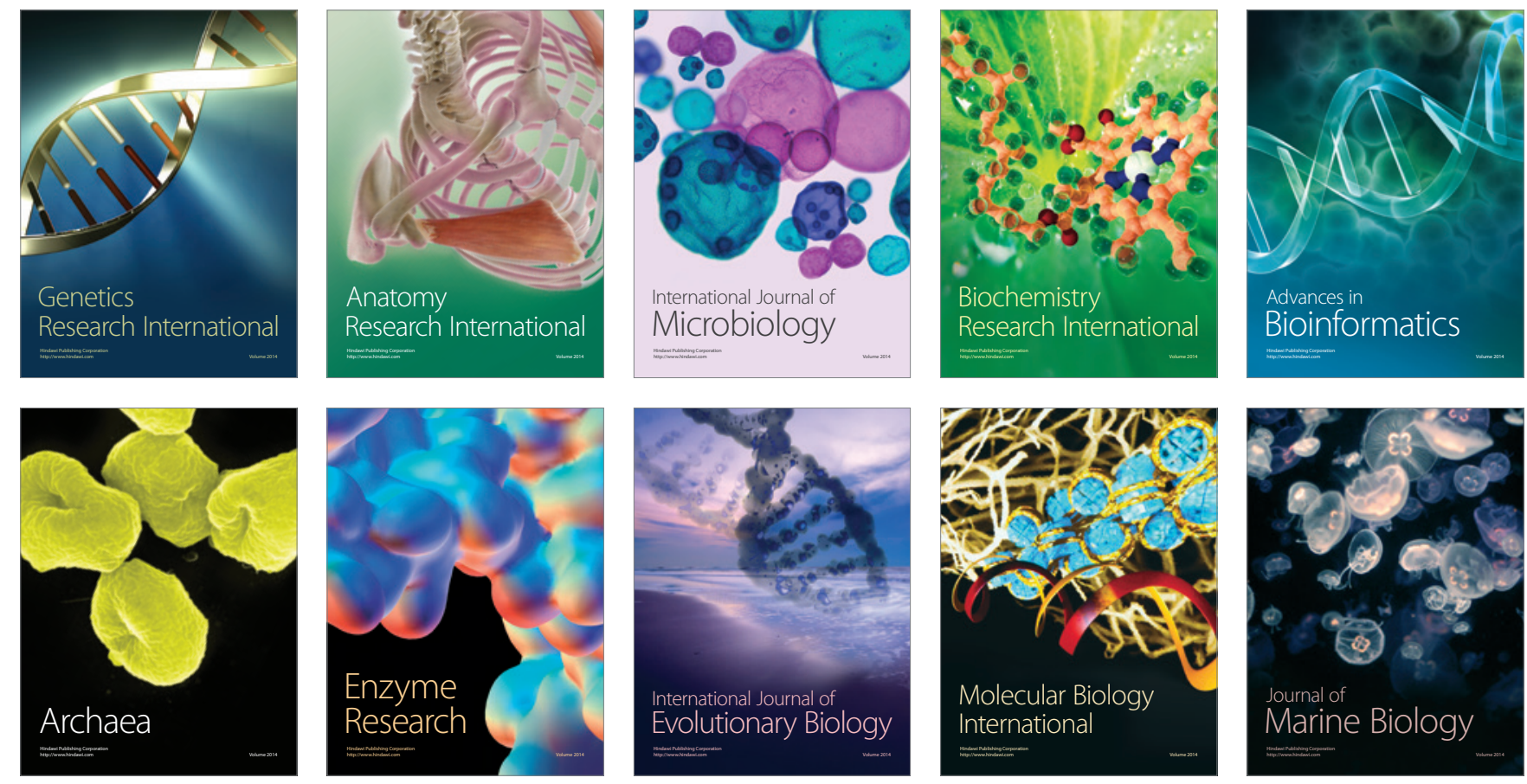